\title{
Analysis and recommendations for European carbon dioxide utilization policies
}

\author{
Castillo Castillo A. ${ }^{1{ }^{*}}$ and Angelis-Dimakis A. ${ }^{2}$ \\ ${ }^{1}$ Centre for Environmental Policy, Faculty of Natural Sciences, Imperial College \\ London, South Kensington, London SW7 2AX, UK. \\ ${ }^{2}$ Department of Chemical Sciences, School of Applied Sciences, University of \\ Huddersfield, Queensgate, HD1 3DH, Huddersfield, UK \\ *Corresponding author: a.castillo@imperial.ac.uk, Tel +44 (0)20 75947312
}

\begin{abstract}
Due to lower-cost energy supplies elsewhere, Europe needs resource efficient technologies to safeguard the competitiveness of its energy-intensive industries. The technical feasibility of the CCU value chain components (carbon capture, transportation and utilization) has been widely studied in literature. However infrastructural, regulatory and business strategic issues have received less attention. A review of the relevant policies (e.g. European Emissions Trading Scheme, Renewable Fuels and Waste Directives) has been performed. Stakeholder engagement and the stakeholder influence mapping was used to examine potential climate change, circular economy, renewable energy and regional industrial development policies that can support $\mathrm{CO}_{2}$ utilization value chains. The main contribution of the paper is to outline potential benefits of policies to foster the production and uptake of $\mathrm{CO}_{2}$-derived products such as methanol, polyurethane and mineral construction aggregates. Another outcome is to illustrate the role of key policymaking stakeholders in assessing the suitability of current statutes and the impact of potential changes. An important finding was that the development of connectivity infrastructure is a key missing enabler and more attention to policy on infrastructure is required. Finally, the work examines the justification for a $\mathrm{CO}_{2}$ Utilization Directive, comparable to the Carbon Capture and Storage Directive, but considering the current complexity of the European Union (EU) policy landscape.
\end{abstract}

Keywords: Carbon Capture and Utilization (CCU), Stakeholder Influence Mapping, Resource Efficiency, Circular Economy, End-of-waste, EU Emissions Trading Scheme, Regional Smart Specialization Strategies

\section{Acronyms:}

CCU

Carbon Capture and Utilisation

CCS

Carbon Capture and Storage

CEF

Connecting Europe Facility

DG CLIMA Directorate General for Climate Action

DG ENV Directorate-General for Environment

DG GROW Directorate-General for Internal Market, Industry, Entrepreneurship and SMES

DG REGIO Directorate-General for Regional and Urban Policy 


$\begin{array}{ll}\text { EEA } & \text { European Environment Agency } \\ \text { ETS } & \text { Emissions Trading Scheme } \\ \text { ILUC } & \text { Indirect land use change } \\ \text { MEP } & \text { Members in the European Parliament } \\ \text { NER } & \text { New Entrants Reserve } \\ \text { NGO } & \text { Non-Governmental Organizations } \\ \text { RDA } & \text { Research and Development Agency } \\ \text { RES } & \text { Renewable Energy Sources } \\ \text { WFD } & \text { Waste Framework Directive }\end{array}$

\section{Introduction}

Europe needs to deploy resource efficient technologies that maximize the use of energy, wastes and by-products already present in the economy, e.g. use of excess renewable energy or process heat. The international availability of low-cost, partly unconventional hydrocarbons (i.e. sources requiring additional extraction methods which are not normally used in traditional oil and gas extraction, such as shale gas) puts pressure on the competitiveness of European production processes and on industrial feedstocks. Specifically, the availability of inexpensive natural gas has resulted in the availability of low-cost bulk chemicals such as ethylene and ethane (Garcia, 2013). The chemical industry is particularly affected due to its high energy use and because it uses internationally traded petrochemical feedstocks. A parallel pressure is the need to reduce greenhouse gas (GHG) emissions. The EU low-carbon economy roadmap stipulates a reduction to $80 \%$ below 1990 levels, by 2050, across all sectors. More specifically, energy intensive industries should cut emissions by more than $80 \%$ by 2050 (EC, 2011).

The wide implementation of Carbon Capture and Utilization (CCU) is proposed as a way to help alleviate the impact of these trends. The European $\mathrm{SCO}_{2} \mathrm{~T}$ project (Wilson et al., 2016) concluded that CCU can make important contributions in Europe, by becoming a significant component in the future low-carbon circular economy and facilitating the energy transition. Important barriers to the development of CCU have been identified in literature and stakeholder engagement. These include, amongst others, (i) the relative dimension of its abatement contribution, in order to illustrate its contribution to emission reduction targets; (ii) the required infrastructural development (UK Government, 2018) in order to connect untapped sources with utilisation processes; (iii) several legal definitions for various uses and types of feedstocks (A. Bönke, personal communication, October, 2016) to enable CCU to be eligible for support and regulation, e.g. under various European Directives; and (iv) public acceptance (Wilson et al., 2016; Bui et al, 2018) to allow development of infrastructure and uptake of products containing $\mathrm{CO}_{2}$. In addition, $\mathrm{CO}_{2}$ reuse has the potential to be a key component of large-scale CCS demonstration projects in emerging and developing economies, where there is strong demand for energy and construction materials and less likelihood of the early adoption of carbon pricing (GCCSI, 2011). 
This paper sets out to identify policy interventions that will help remove the technical, economic and societal barriers in order to deploy CCU from the perspective of affected and involved stakeholders. The contributions of the paper are twofold. First, the authors delineate the pathway of abstraction from technical and logistical barriers, apparent initially only to technical proponents, through to conditions for the creation of resource management at regional level. For instance, the institutional and societal requirements needed for consolidating waste and by-product flows and turning them into acceptable feedstocks and eventually consumer products are identified. The result is a structured approach to supplement existing policies and statutes affecting the emitters, the potential industrial users and the general public. The second contribution is to engage directly with stakeholders who can benefit from the development of CCU as well as with those whose acceptance, buy-in or commercial demand is required. Cross-referencing and comparing the constraints of different stakeholder groups is the means to ensure that recommendations to supplement policy are collectively constructive across the value chain.

\subsection{Need for CCU Policy}

According to the literature and to their own statements, participants of future CCU value chains depend on three basic policy areas to enable them to continue their involvement:

- Market regulation

- Support for early technical development

- Incentives and guidance for broader deployment

Market regulation allows local governments to define and firms to follow the rules of CCU commercial activity. For instance, defining what is a tradeable waste product is of outmost importance. This ensures that competition and pre-competitive development of novel technologies, which help minimize externalities of existing ones, can take place under fair and relatively stable conditions to foster investments. This is delivered through instruments such as standards for performance and quality as well as criteria to benchmark the sustainability, recyclability and renewable content characteristics of products.

Support for early development is mainly needed by firms and early value chain participants, who are not in a position to bear the cost or the risk of project infrastructure and other assets or capabilities that are only amortized in the long term. Therefore, assistance needed in early stages includes infrastructure planning and financing mechanisms; support for scale-up research and development; and support for public engagement highlighting problems solved and services provided.

Incentives and guidance for deployment are above all needed in instances where societal benefits are an important component of the overall propositions. Among the useful incentives and guidance for deployment are targets for the achievement of policy outcomes; Life Cycle Assessment (LCA) backed product differentiation; support for piloting and demonstration, and public procurement.

Alongside these three areas of support, there are specific objectives for CCU policies meant to ensure that CCU technologies are attractive from a commercial, 
environmental and public acceptance standpoint. They fall under the categories of sustainability and industrial innovativeness and productivity.

Under sustainability, the main objectives include greenhouse gas emission reduction, resource efficiency, energy efficiency and overall pollution reduction. It is important to regard energy efficiency as separate from decarbonization in this context, mainly to appreciate the energy intensity of new solutions even when they are based on renewable or nuclear energy. In terms of industrial innovativeness and productivity the main objectives include differentiation of European technology, economic competitiveness of services and products and infrastructural improvement.

\subsection{Application perspectives for CCU policy}

There are two application perspectives that can be used to formulate individual policies systematically, in order to address all aspects of CCU development. These perspectives ensure that enough attention is given to all stages of development and to the needs of all stakeholders in the CCU sector. The literature on environmental technologies (Zhang and Sims Gallagher, 2013; Rex et al., 2015; Adner, 2006; Seppälä and Kalm, 2013) distinguishes between: (i) policies to address the innovation cycle; and (ii) policies to address elements of the value chain. This paper focuses mainly on policies that address all elements of the value chain as well as on analysis of the gap between existing policies and additional needs specific to CCU.

Full discussion of policies along the innovation cycle, which enable value chains to continue their development from fundamental science to commercialization (Figure 1), requires first that all pathways of $\mathrm{CCU}$ are well defined and widely recognized. It, then, requires a discussion on how generic types of policy instruments, which target each developmental stage, can be adapted to the varied CCU value chains and their multiple applications. As with other innovations designed to deliver a societal or environmental benefit in addition to profit, special attention should be paid to the technology valley of death and the commercialization valley of death. The former refers to the financially uncertain period after initial venture funding has peaked and investors are reluctant to keep funding product development due to the high technical and management execution related risks and long development horizons (Jenkins and Mansur, 2011). The latter refers to the gap between the pilot or demonstration and the commercialization phases. It reflects the distinction between the purpose of venture capital and that of later-stage project finance and debt or equity investors before commercial transactions can sustain a firm (Jenkins and Mansur, 2011). 


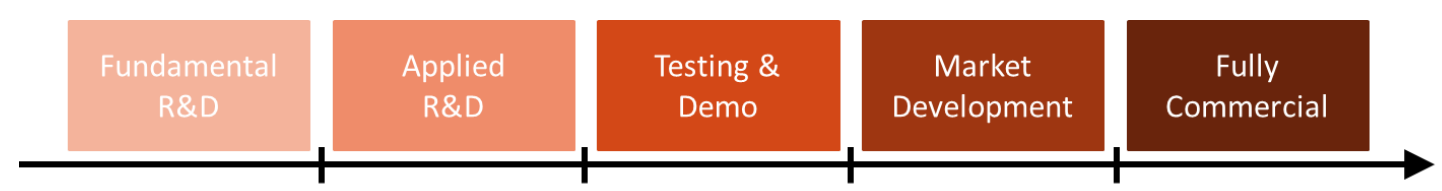

Early Development Support

Market Formation and Regulation

Incentives and Guidance for Deployment

Figure 1. Policy vehicles along the innovation cycle

The objective of this paper is to define the elements of a CCU value chain that merit policy consideration in light of their implications for the wider implementation of CCU. It is intended to inform stakeholders of CCU value chains and other members of the emerging CCU community about the policy mechanisms that are in place and at the same time how these mechanisms need to be amended or enhanced in order to facilitate CCU. This study contributes to the basis of, but does not replace, a fully developed policy strategy for the long term. It also does not attempt to replace a full CCU innovation policy plan for Europe.

The analysis consisted of a literature review, the identification of key stakeholders and the creation of a wider network of relevant scientists, industrial stakeholders and policy makers, through participation in conferences and workshops, hosted by European Commission General Directorates, research consortia and industries. The next step was to perform semi-structured interviews with members of this network. It should be noted that some interviewees from three General Directorates of the European Commission clarified that they agreed to discuss CCU expressing their personal opinions and these should not be interpreted as official statements of the European Commission. Therefore, they appear anonymized and individual statements are not directly attributed.

Section 2 presents an overview of the options for CCU with existing policies as a starting point and provides a brief reminder of the policy-making process. Section 3 identifies the specific policies that can be improved to increase the viability of CCU value chain elements, by highlighting the major policy gaps. Section 4 lists the main recommendations from reviewed sources and interviewed stakeholders that could be applied in order to address these policy gaps. Section 5 provides an overview of the different parties to the CCU policy landscape, which contains distinct kinds of stakeholders. This helps to explain how the feedback cycle should work to enable policy makers to convey the evidence they need to generate the right policies and, conversely, policy users to understand which existing mechanisms are already suitable and which ones need to be amended. Finally, Section 6 presents the final remarks and recommendations targeting specific policy instruments.

\section{Methods}

Within the European project enCO $\mathrm{C}_{2}$ re (Enabling $\mathrm{CO}_{2}$ Reuse), work by the authors to map out the development of $\mathrm{CCU}$ value chains identified barriers to technical 
deployment. Experience of industrial proponents has concluded that the economic viability of the technology is related to the: (i) development of demand for CCU-derived industrial feedstocks and final products; (ii) development of commercial scale logistics and connectivity infrastructure; and, importantly, (iii) public acceptance of both infrastructure and CCU-derived products.

Stakeholders with a high level of interest and influence were identified through two different avenues: (a) participation in commercial conferences (e.g. $\mathrm{ACl}$ Carbon Dioxide Utilization Summit in Brussels), project dissemination conferences (e.g. $\mathrm{SCO}_{2} \mathrm{~T}$ ) and round tables organized by interested institutional stakeholders (e.g. the European Directorate General for Internal Market, Industry, Entrepreneurship and SMEs); and (b) review of the scientific and grey literature on policies for CCU, which confirmed the scarcity of work focusing on policy development for CCU.

The focus on economic, commercial and public acceptance barriers resulted in identifying the following key stakeholder groups.

(i) Institutional stakeholders responsible for policy making and monitoring as well as societal wellbeing:

- European Directorate General officers for Climate Action; Environment; Energy; and Internal Market

- National Ministries for Environment and Economic Affairs

(ii) Industrial stakeholders participating at different stages of the value chain:

- Industrial installations emitting $\mathrm{CO}_{2}$-containing streams

- Industrial installations with potential to use $\mathrm{CO}_{2}$

- Regional multi-sector industrial parks

- Port regions with international logistics and chemical production facilities

- Technology companies offering materials or equipment for CCU

The stakeholder engagement and elicitation work involved conducting telephone or face to face semi-structured interviews with representatives from all stakeholder groups. They interviewees have been provided with an overview of the objective of this work to identify policy interventions to foster $\mathrm{CCU}$ and then their views were sought on remaining dependencies and possible next steps. The discussion always included the way they could contribute and the factors affecting their individual and collective ability to make progress. Details on the elicitation for the influence mapping are provided under section 5.3.

The sequence of events began with reviewing the barriers hindering progress in industry, which helps identify dependencies. Then, the stakeholders with more direct involvement were sought out and the process replicated to identify their barriers. Semistructured interviews are suited as they allow for free-format inclusion of unforeseen dependencies and other kinds of factors previously unaccounted for, such as political cycles, monetary policy or other context-specific factors that may or may not be generalizable but are available for the researcher to classify and tackle systematically. Motivations and concerns of different stakeholder groups were cross-referenced and compared to ensure that recommendations to supplement policy can address the hindrances affecting all parts of the value chain. 


\section{Policy options for CCU - Key messages}

CCU technologies are clearly at different levels of maturity and will require specific policy instruments to foster commercial viability and balance effort across stages of the value chain of distinct CCU pathways. In general, the components of the value chain that merit targeted policies can be grouped into:

- Carbon dioxide sources - including aspects of treatment and purification

- Carbon conversion into new products - including aspects of treatment and purification

- Users and uptake routes for products

- Infrastructure development

- Public acceptance

\subsection{Policy formation and existing policy mechanisms}

The variety of pathways reflects the variety of mechanisms needed to regulate and support CCU. Broadly, there is a more substantial debate about emission sources and about some uptake routes. Frequently expressed priorities of the scientific community working on $\mathrm{CCU}$, as indicated, for instance, by conference topics, emphasize the need to change policy to enable some product groups to be viable (Armstrong et al., 2016). At the same time, however, the infrastructure debate is much less prevalent, as shown by the lower number of publications and conference topics, and represents a clear gap that is hampering more demonstrations of CCU, and CCS routes (Bui et al, 2018), already at a higher TRL, which would enhance public acceptance and make progress in the planning systems of various countries.

In principle, the step-wise process, proposed by Miller (2013), towards developing strategic innovation policies includes:

1. Identify the development goal(s) within the region of interest;

2. Characterize the likely technology changes required to enable the achievement of these goals;

3. Identify the types of innovation activities that are appropriate for accelerating these technology changes;

4. Assess the innovation capacity necessary to achieve these innovation activities; and

5. Identify and convene the likely set of stakeholders involved in promoting policies to meet these innovation capacity needs.

In the context of the European Commission the process includes, in the first instance, the preparation of an impact assessment of the problem to identify all possible options. For example, ash mineralization is not yet considered to have a significant impact on the climate (GCCSI, 2011). Significant analysis is needed to further justify and ensure the viability of ash mineralization in respect to all stakeholders. Performing this kind of analysis is crucial before being able to compose a proposal for the European Parliament, which is the next stage in the policy-making process. The second step is for the European Commission to create a committee to gather evidence, discuss options and formulate a proposal. Then in some cases there is a consultation to increase the evidence base and the views of the stakeholders. When proposals are 
ready they are sent to Parliament for debate. Parliament might require amendments from the Commission. Finally, the proposals need to be approved as well by the European Council.

\subsection{Policies across the CCU value chain}

Figure 2 presents the policy vehicles that correspond to specific value chain stages. Existing policies are typically designed to address specific CCU pathways. This work investigates ways to amend existing policies. In the cases where a distinct new area is not covered there may be a need to create new policies altogether. For instance, if there was a new incentive for the utilization of $\mathrm{CO}_{2}$ there could be different directives hosting it but an example of a prominent policy that must be explored fully before seeking to create a new one is the Waste Framework Directive (WFD).

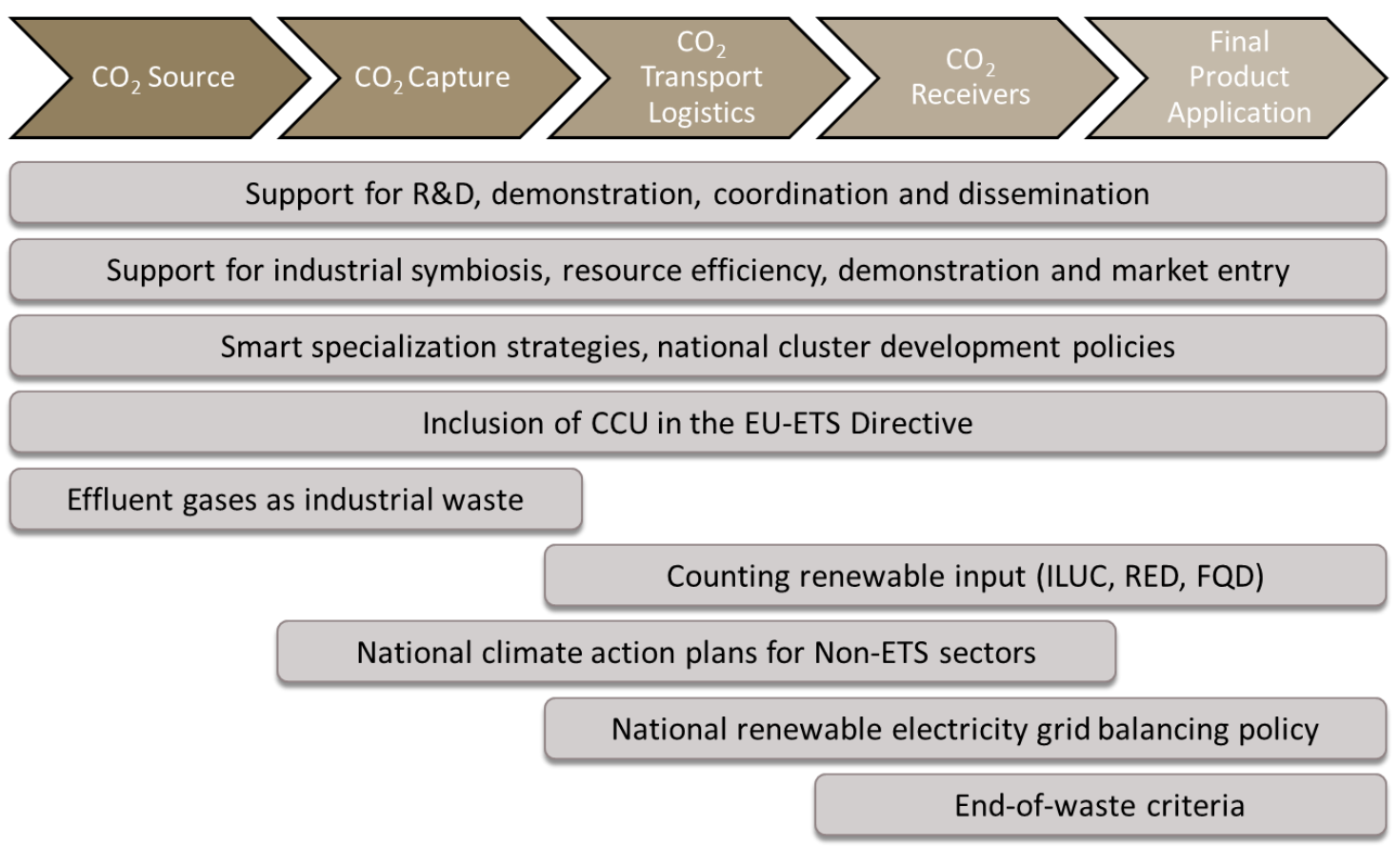

Figure 2. European policies suitable for each stage of the CCU value chain

\section{Gap analysis between needs and existing policy}

\subsection{Waste Framework Directive}

\section{Current situation and limitations}

Analogous to existing policy for distinct renewable energy sources, there is a need for a differentiated policy framework for recycled materials, according to the type of material or product. Multiple nuances are not yet fully detailed in circular economy policy, such as different types of business-to-business plastic, chemicals and byproducts in addition to post-consumer waste. As of 2016, the Waste Framework Directive (WFD) considered industrial flue gases from sectors which do not belong to the European Emissions Trading Scheme (Non-ETS sectors), as emissions and not as wastes (European Parliament, 2008).

\section{Relevant trends}


The Directorate General (DG) Environment has supported a proposal to the European Parliament at the end of 2016 for the inclusion of gaseous effluents as waste to make them eligible for measures under recycling initiatives as well as the Circular Economy Package (A. Bönke, personal communication, October, 2016). Member States, the European Commission and the European Parliament itself can suggest amendments as part of the revision. No new revision will be considered in the foreseeable future (DG GROW, personal communication, December, 2016).

\subsection{European Emissions Trading Directive}

\section{Current situation and limitations}

The Directive 2003/87/EG on the European Emissions Trading Scheme (ETS Directive) describes the cap and trade system that includes the most carbon intensive industries with over 11,000 emission sites across Europe, which are accountable for approximately $50 \%$ of $\mathrm{CO}_{2}$ emissions across the $\mathrm{EU}$ (European Parliament, 2003). The first difficulty for CCU within the ETS Directive is the statement that captured and transferred emissions of fossil $\mathrm{CO}_{2}$ could be subtracted from a particular installation when they were transferred as component of a fuel onto an installation that is included in the ETS (e.g. the supply of a $\mathrm{CO} / \mathrm{CO}_{2}$ mixed stream from a steel mill to a power plant). The transferred emissions are then subtracted from the emitter that supplies the $\mathrm{CO}_{2}$ and added to the balance of receiving installation. This procedure, however, does not apply to most CCU routes such as carbonation, algae or ethanol production. This is because the receiving processes are not amongst the most carbon intensive installations and are therefore excluded from the ETS. Thus, the transferred $\mathrm{CO}_{2}$ has been considered as emitted not as stored making the operation liable for emissions certificates.

\section{Relevant trends}

Different accounting methods are being proposed to find a solution for various uptake routes of $\mathrm{CO}_{2}$ for $\mathrm{CCU}$. The main attribute is the ability to demonstrate and then account for the ability to fix $\mathrm{CO}_{2}$ in a new feedstock or product.

\subsection{New Entrants Reserve 300}

\section{Current situation and limitations}

A mechanism within the ETS Directive 2009/29/EG suitable for large scale demonstration projects is the New Entrants Reserve 300 (NER300) and as of 2016 it did not include technologies for CCU value chains (Armstrong et al, 2016). The NER300 administers the auction proceeds from 300 million emission certificates for sustainable energy projects including Carbon Capture and Sequestration (CCS) and renewable energy technologies. Its budget can be used for up to $50 \%$ of the "subsidizable" costs of a project supplemented by private investment or national governments. Member States do the first evaluation of proposals in their jurisdiction and then submit a selected sub-set to the European Investment Bank (UBA, 2018).

\section{Relevant trends}


Different stakeholders consider that CCU should be included in the subsequent version of the New Entrants Reserve, namely the NER400 (T. De la Fuente, personal communication, January 30, 2017; UBA, 2018).

\subsection{Directives on Indirect Land Use Change, Renewable Energy and Fuel Quality}

\section{Current situation}

A critical policy is the Directive to reduce indirect land use change (ILUC) for biofuels and bioliquids (EU) 2015/1513, known as the ILUC Directive, which amends Directive 98/70/EC relating to the quality of petrol and diesel fuels known as the Fuel Quality Directive (European Parliament, 2015) and Directive 2009/28/EC on the promotion of the use of energy from renewable sources (known as RES Directive). The Fuel Quality Directive 98/70/EC, Article 7a (2), required by 31 December 2020 the reduction by at least $6 \%$ of the life cycle greenhouse gas emissions per unit of energy. The RES Directive (2009/28/EC) Article 3.4 stipulated that the renewable energy proportion in the energy used for transport depends on the amount of renewable energy present in either the energy mix of the EU or of the member state.

\section{Relevant trends}

The ILUC Directive states that for CCU-fuels to qualify for double counting (i.e. counting twice the production of fuels derived from feedstocks such as non-food cellulosic materials and waste), the energy source must be renewable, which refers to the energy source for the production of the fuel not to the source of carbon. The implication of this is that capturing carbon from fossil origin to be repurposed as CCUfuel using renewable energy is allowed and qualifies for double-counting in terms of mitigation of carbon emissions.

A RES Directive recast proposed by DG Energy COM (2016) 767 (EC, 2016) includes an obligation on fuel suppliers to supply a proportion of advanced fuels, which can reassure investors and encourage the development of transport fuels such as renewable liquid and gaseous fuels of non-biological origin. This encompasses fuels from fossil-derived waste gases and sets blending percentage obligations on suppliers at the same level in each Member State to ensure consistency in fuel specifications, availability and ease of trade across the EU. These proposals might be adopted at least a year after submission. They include CCU technologies such as Power to X, hydrogen utilization and formic acid production.

\subsection{Infrastructure and connectivity}

\section{Current situation}

Most CCU-relevant policies so far focus on emitters/sources (e.g. EU-ETS) or products (e.g. Fuel Quality Directive). This creates an imbalance in terms of the support needed for the crucial element of connectivity. One of the main gaps, where support from governments at regional, national, and European Union level would be beneficial, is in the minimization and sharing of risks of symbiosis or collaboration projects. (T. De la Fuente, personal communication, January 30, 2017; Wilson et al., 2016). In these cases, infrastructure is required considering the throughput of each one of the partners (Patricio et al., 2017). This is relevant because neither individual companies nor small 
local authorities can finance or underwrite the risk of infrastructure to connect emitters and receivers or clustering amongst emitters.

\section{Relevant trends}

Regional industrial clusters such as the Tees Valley and the region near the Port of Le Havre recognize the need to improve connectivity between existing industries as well as with potential additional sources of $\mathrm{CO}_{2}$ and markets for $\mathrm{CCU}$-derived products $\mathrm{H}$. Moens, personal communication, November 28, 2016; M. Hidrio, personal communication, October 6, 2017; M. Lewis, personal communication, September 26, 2017).

\section{Stakeholder analysis}

Representatives from all the stages of an industrial CCU value chain, directly (i.e. emitters of carbon, potential users of carbon) or indirectly involved (e.g. regional authorities, municipalities) are interested in understanding how they can engage with the policy landscape to help shape policies.

$\mathrm{CO}_{2}$ emitters include all industrial plants, usually classified based on the purity and the magnitude of effluent flow. The major emitters, considered in a CCU value chain study, include power plants, cement industry, iron and steel industry and other high purity sources (e.g. fermentation based processes, hydrogen production). The $\mathrm{CO}_{2}$ receivers can be categorized in four major groups: (a) direct use of $\mathrm{CO}_{2}$ (e.g. food industry, beverage production, $\mathrm{pH}$ control), (b) mineral carbonation (e.g. $\mathrm{CO}_{2}$ concrete curing, bauxite residue treatment), (c) fuels production (e.g. methanol, formic acid, algae production), and (d) non-fuel related chemicals production (e.g. polyurethane, polycarbonate). Patricio et al. (2017) and Pieri et al. (2018) have compiled an extensive list with all the existing and emerging $\mathrm{CO}_{2}$ uses, including several quantitative and quantitative characteristics. It was observed that the main focus in the wider debate is still on emitters and receivers while less emphasis is placed on conversion processes, connectivity and enabling mechanisms. It is thus critical to identify the role of all CCU value chain stakeholders, particularly those that have an influence from the perspective of non-CCU value chains. This includes, first, companies intending to participate in CCU as emitters or receivers, which need to comply with regulations on emissions, recycling, energy generation, fuels, urban planning and public support. The second group includes companies that can supply auxiliary inputs, for instance surplus hydrogen or renewable electricity, as well as the general public and some NonGovernmental Organizations (NGOs). These two subcategories are therefore regarded as policy receivers. The final subcategory consists of policy makers themselves.

Since the policy landscape is already dense (M. Velkova, personal communication, December 5, 2016), it is widely accepted that stakeholders, such as industrial firms and their overarching industry associations, should use all the mechanisms in the existing policies, such as the Waste Framework Directive, before proposing new ones. This implies that understanding all policies, including those not immediately related to $\mathrm{CCU}$, is a pre-condition for updating policy. The following step is to define how to engage with the right policy makers at European level and then at national level to 
ensure that the transposition of European directives into national regulations reflects their objectives. Before proposing changes in policy, the onus of providing evidence for the need of amendment lies with value chain participants themselves (see Section 3.1). It is also widely acknowledged that the onus to prove sustainability of CCU products via Life Cycle Assessment lies with product proponents (Armstrong et al., 2016).

\subsection{Policy makers}

In the absence of a single contact point for CCU policy, different organizations need to be equipped with expertise on broader policy objectives on climate change, energy and resource efficiency.

Various General Directorates of the European Commission were identified as starting point of policy making as well as managers of amendments of existing policy during work within the enCO $\mathrm{C}_{2}$ re project, as result of literature review and throughout the stakeholder engagement via cascading identification where stakeholders helped identify additional stakeholders. The most relevant instances are:

- Directorate-General Climate Action (DG CLIMA), which aims to formulate and implement cost-effective policies for the EU to meet its climate targets for 2020, 2030 and beyond, especially on greenhouse gas emissions and the ozone layer. It also ensures climate change is taken into account in all other EU policies. It is advisable to engage with DG CLIMA in all CCU efforts directly related to net changes in emissions, even if DG CLIMA is not responsible for specific policies at hand. DG CLIMA is responsible for the Fuel Quality Directive and the ETS Directive.

- Directorate-General Energy, which develops and implements the EU policy for secure, sustainable, and competitive energy. It aims to safeguard a market providing affordable energy, competitive prices and technologically advanced energy services. It is responsible for the Renewables Directive and the ILUC Directive.

- Directorate-General Environment, which facilitates the implementation of policies and legislation that contribute to enabling EU citizens to live well, within the planet's ecological limits, based on an innovative, circular economy, where growth has been decoupled from resource use; biodiversity is protected, valued and restored; and environment-related health risks are minimized in ways to enhance society's resilience. It is responsible for the Waste Framework Directive and the Green Public Procurement.

- Directorate-General for Regional and Urban Policy (DG REGIO), which aims to ensure that people in all regions can realise their full potential through improvement in the economy and quality of life and is responsible for Smart Specialisation Strategies. It works with Member states and regions to assess needs, finance investments and evaluate results from a long-term EU perspective.

- Directorate-General for Internal Market, Industry, Entrepreneurship and SMEs (DG GROW) is responsible for implementing the industrial and sectoral policies of the flagship Europe 2020 initiative and for any Public Procurement 
Regulations. It fosters entrepreneurship and growth by reducing the administrative burden on small businesses, facilitates access to SME funding and supports access to global markets for EU companies, as contained in the Small Business Act.

A full investigation of national ministries responsible for transposing policy to national markets was beyond the scope of this work. However, the authorities responsible for analogous matters, as the DGs described above, should cover the corresponding aspect of CCU in each Member State. In addition, Regional Development Agencies are the only organizations able to provide an overview of relevant priorities in an area and to influence infrastructure development, as this is often not practicable at local and national levels.

\subsection{Policy Influencers}

Apart from policy receivers and policy makers, there is a broad range of influencers, such as incumbent technology proponents, the general public and NGOs, whose influence needs to be mapped out before analyzing the policy formation cycle. A brief outline of their relevance is attempted below.

Competing technologies possess their own policy-influencing mechanisms. This underlines the importance of gathering rigorous evidence for impact statements for CCU-promoting policies.

The general public is difficult to address in a simple way. Providing rigorous evidence is only the first step. Real engagement is most effective at local level through regional development agencies or local industry coordinating bodies. For example, Tees Valley Unlimited is an industry grouping that fulfils part of the role of a regional development agency in an important chemical and industrial cluster region.

Engagement with NGOs can vary depending on their size and standpoint towards new technologies. The most conservative environmental NGOs may require an ad-hoc strategy so as to avoid confrontational stances. A task for CCU proponents is to perform rigorous scientific analysis to address all reasonable arguments against the development of CCU. NGOs open to new technology should be seen as facilitators to work with the public and business.

Industry Associations have legal differences compared to their individual members. By representing many companies, they represent a sizeable work force and often the function of a strategic sector of economic activity for some regions. This allows them to put forward arguments relevant to the broader economy and competitiveness, in many cases, at European level. Their engagement should continue to grow and the expectation of rigor of the information they put forward is proportional to their size and resources.

\subsection{Stakeholder influence analysis}

Stakeholder influence analysis is helpful in prioritizing how to collaborate with relevant actors in CCU development. The work involved stakeholder engagement through participation in round tables, and by conducting telephone or face to face semistructured interviews with representatives from all stakeholder groups. They ranged 
from small potential $\mathrm{CO}_{2}$ user firms to officials of European General Directorates. They included some of the most active ports, chemical clusters and industrial stakeholders. They were asked to identify the dependencies and remaining barriers to $\mathrm{CO}_{2}$ utilization as well as the possible steps to overcome them. They pointed out whose interests and whose responsibilities were the most important to make progress and commented on their own level of influence, for example in their ability to change policy or develop standards. The results of the elicitation performed are presented in Figure 3.

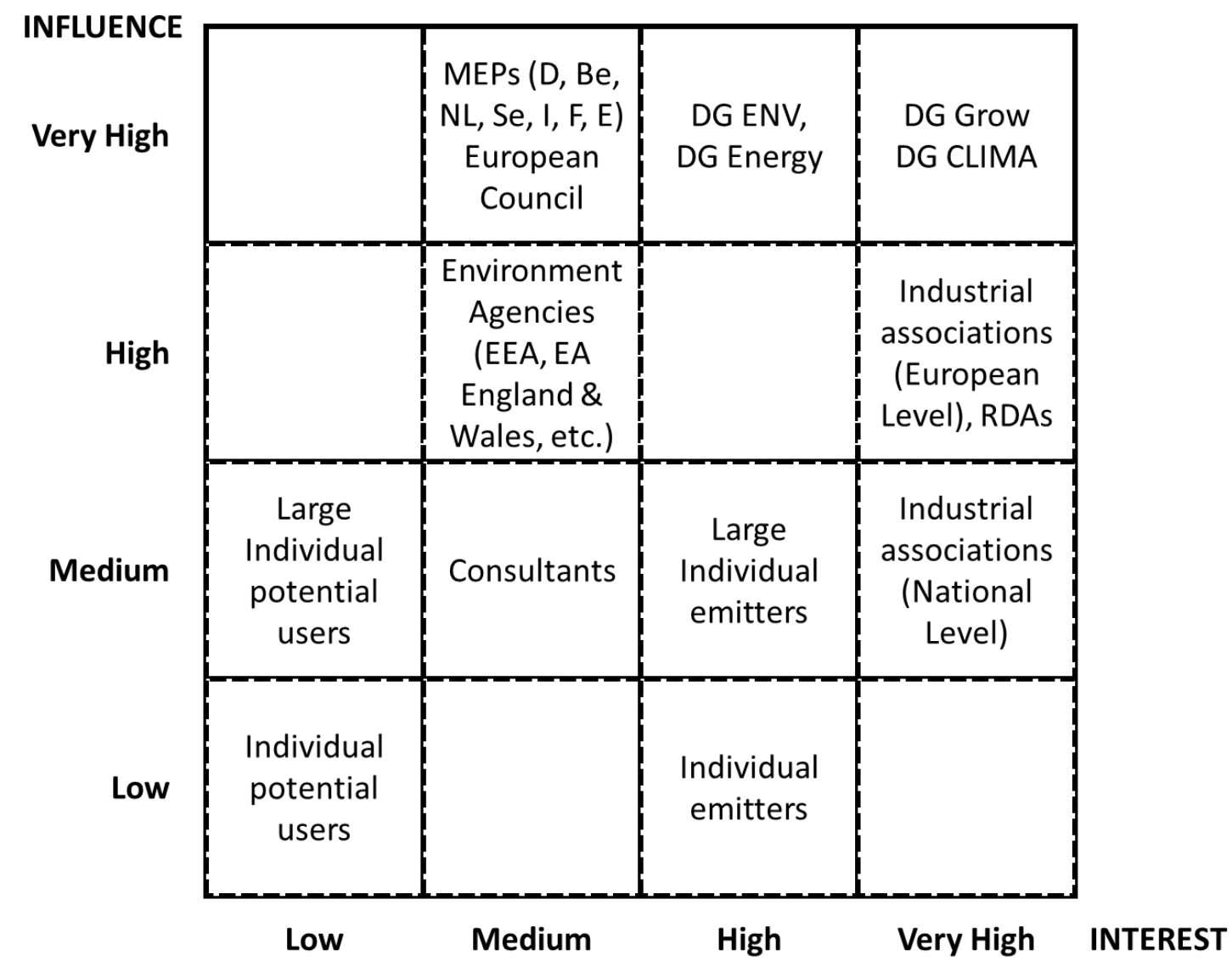

Figure 3. Stakeholder influence map for CCU value chain in Europe

The results reflect that some of the most interested stakeholders such as large emitters do not have the ability to influence policy or infrastructure in isolation. Industry associations such as the European Chemical Industry Council consolidate the interests of firms as well as the international workforce of their sector. They can provide evidence or justification for new policies or infrastructure at an international level. Some General Directorates have as objectives to enable economic development and propose the appropriate policy framework that can promote the benefits and regulate the impacts of industrial activities. For instance, they need to create the framework that will allow that some emissions are regarded as a potential feedstock rather than an irretrievable pollutant.

Another salient finding of the stakeholder elicitation was that the CCU debate is still mostly dominated by the pressures on the emitters. However, it has become clear that large emitters are more interested in CCS than in CCU. This is understandable in the context of the aim or potential for large emission removal. Nonetheless, emitters are 
important actors in CCU because of their local economic significance (K. Callebaut, personal communication, September, 2016). This allows them to guide the dialogue with potential users and regional government in terms of environmental permitting, e.g. the use of construction aggregates derived from $\mathrm{CO}_{2}$, and infrastructural needs such as authorizing new pipelines.

By contrast, potential users are in some cases not aware that they could use locally captured $\mathrm{CO}_{2}$ as feedstock and due to quality control and purity considerations, they continue purchasing $\mathrm{CO}_{2}$ from trusted industrial gas suppliers. Furthermore, potential users are not under pressure to use locally captured $\mathrm{CO}_{2}$ nor do they automatically have a compelling economic incentive to do so. This research has made explicit the need to engage in a more coordinated way the two most important stakeholder groups, namely, regional development agencies and European level industry associations.

The role of the different European-level industrial associations should be leveraged in two ways. First, they are created to have a unified voice in the European Union and have access to institutions in Brussels. Second, by virtue of the number of companies and individuals that they represent, they address their thematic interest but also their scale is influential in terms of employment and income generation.

\section{Policy recommendations}

\subsection{Waste Framework Directive}

From a broad CCU standpoint, to achieve End-of-Waste status (i.e. when materials are no longer considered waste but actually materials that are safe and appropriate for reuse), products of carbonation or mineralization processes must fulfil the WFD criteria, namely:

- the substance or object is commonly used for specific purposes;

- there is an existing market or demand for the substance or object;

- the use is lawful (substance or object fulfils the technical requirements for the specific purposes and meets the existing legislation and standards applicable to products);

- the use will not lead to overall adverse environmental or human health impacts.

Waste incineration ashes and metallurgic slags as well as construction and demolition waste aggregates passed in 2010 the Joint Research Centre initial threshold assessment to be considered in the development of specific criteria (Villanueva et al., 2010). Subsequently, the industrial and research community must provide evidence about the leaching characteristics of aggregates from carbonation and mineralization to the European Joint Research Centre and DG Environment. Moreover, widespread progress can be achieved by replicating across Member States the third-party accredited testing procedure that Carbon8 completed with the UK Environment Agency explained by Hills (2016).

In general, further amendments beyond the 2016 WFD revision may not be needed as long as the current proposals are adopted; namely, the aforementioned classification of gaseous effluents as recyclable by-products or wastes; and the adaptation of the 
End-of-Waste specification to allow for the recycling of wastes and by-products by mineralization or other value-adding CCU processes.

\subsection{European Emissions Trading Directive}

According to Garcia-Gonzalez et al. (2016), there are three options for amending the general reporting method and its relationship to Non-ETS sectors to address the exclusion of $\mathrm{CO}_{2}$ captured through $\mathrm{CCU}$ from the EU ETS:

i. Taking the emissions from an ETS source completely out of its ETS reporting total and to include in the reporting of the Non-ETS CCU installation only the amount of $\mathrm{CO}_{2}$ that is not fixed in the product and emitted at the processing site. In practice, the source transfers 1 tonne out; the CCU process captures 0.7 tonne. Then, the source reports 0 tonne in ETS; the CCU process reports 0.3 tonnes emitted in Non-ETS accounting.

ii. Including the CCU process in the EU ETS and report within the accounting of the CCU installation the emissions that were not fixed. In practice, the source transfers 1 tonne out; the CCU process captures 0.7 tonne. Then, the source reports 0 tonnes in ETS; the CCU process reports 0.3 tonnes emitted in the EU ETS accounting.

iii. Keeping the net CCU emissions within the EU ETS but within the accounting of the emitter. In practice, the source transfers 1 tonne out; the CCU process captures 0.7 tonne. Then the source reports 0.3 tonne in ETS and the CCU process accounts for fixation and net emission but is not liable for certificates, i.e. reports 0 tonnes in ETS.

In all options, the $\mathrm{CO}_{2}$ fixed in $\mathrm{CCU}$ process that is later emitted during the use phase of the CCU product, e.g. a fuel, is reported under the relevant (non-ETS) sector. Two difficulties with the first two options are that, first, adding significant emissions to a nonETS sector might make it more challenging for some countries to achieve emissions reductions in non-ETS sectors; and, second, emitters would not have incentives to seek new technologies or efficiency gains within their own process or those of the CCU partner. Although the last option implies significant cost of monitoring and reporting at project level in the non-ETS sectors, it has the two advantages that the operating principles of the ETS would undergo minimum alteration, and that the emitter would have an incentive to seek efficient technologies for its own process and a high-fixation CCU partner.

\subsection{New Entrants Reserve 400}

Currently, the scope of the New Entrants Reserve (NER) mechanism is being revised and inclusion of CCU in the forthcoming NER400 for the timeframe 2021-2030 is being recommended by stakeholders such as the $\mathrm{SCO}_{2} \mathrm{~T}$ and the $\mathrm{EnCO}_{2}$ re consortia. In principle CCU demonstrations could be supported as long as they meet criteria defined in the program. A series of structured calls for CCU scale-up proposals may be a suitable additional mechanism to accelerate the market development of CCU products as they progress along the innovation cycle towards commercial maturity (Armstrong et al, 2016). This would also help prevent carbon leakage, or off-shoring, of carbon intensive industries whilst promoting innovation in resource efficient products. 


\subsection{Directives on Indirect Land Use Change, Renewable Energy and Fuel Quality}

The authors' assessment is that the proposal by DG Energy included in the trends identified in section 4.4 addresses previous shortcomings.

\subsection{Infrastructure and connectivity}

\subsubsection{Smart specialization strategies}

As stated in Section 3, one of the main gaps in policy support is the de-risking of symbiosis or collaboration projects. De-risking could be assisted through explicit infrastructure support within demonstration projects and involvement of Urban Planning stakeholders in the discussion of climate, resources and energy policies. Cluster formation initiatives are plentiful but they seem to be mostly fragmented. However, many technical solutions depend largely on the assistance of coherent cluster formation support (GCCSI, 2011).

National/Regional Research and Innovation Strategies for Smart Specialization (RIS3 strategies) are integrated, local economic transformation agendas that address five points (EC Smart Specialization Platform, 2017)

- They focus policy support and investments on key national/regional priorities, challenges and needs for knowledge-based development.

- They build on each country/region's strengths, competitive advantages and potential for excellence.

- They support technological as well as practically oriented innovation and aim to stimulate private sector investment.

- They get stakeholders fully involved and encourage innovation and experimentation.

- They are evidence-based and include sound monitoring and evaluation systems.

After using the guidance and tools provided by the Smart Specialization Strategies Platform (S3Platform), regions can prioritize how they apply for structural development funds. Therefore, the strategies can become a critical way to help de-risk parts of the industrial connectivity infrastructure that are hard for individual companies or local governments to finance (T. De la Fuente, personal communication, January 30, 2017).

Finally, one key aspect of the strategies is that they provide the framework within which Regional Development Funds can be justified and requested as long as infrastructure is spelled out as a priority for the strategy.

\subsubsection{Connecting Europe Facility}

Pipeline infrastructure is subject to land and subsoil rights which are the responsibility of regions also because they are a potential natural monopoly. Industry should therefore advocate for including CCU infrastructure in the Connecting Europe Facility (CEF) leveraging parts of the regional strategies. Since January 2014, the Innovation and Networks Executive Agency (INEA) is the gateway to funding under the CEF. INEA implements most of the CEF programme budget, including €22.4 billion for Transport, $€ 4.7$ billion for Energy and $€ 0.3$ billion for Telecoms. 


\subsection{Additional recommendations}

\subsubsection{Dedicated performance measurement and support calculations}

CCU stakeholders, including staff of the General Directorates mentioned on previous sections, are interested in creating more clarity across CCU-related policies. It is proposed that to harness the environmental, societal and economic benefits of $\mathrm{CCU}$ there should be no distinction between biological $\mathrm{CO}_{2}$ and other $\mathrm{CO}_{2}$ streams and policies that encourage inter-sectorial use of $\mathrm{CO}_{2}$ must be introduced (Ghinea, 2016). A formula and a tabular decision guide would help qualify CCU technologies for particular levels and kinds of support. Conditions for support include (i) the need to ascertain whether state aid is in fact needed and proportionate; and (ii) all cases where a situation of double support could emerge must be addressed accordingly ( $M$. Velkova, personal communication, December 5, 2016). Key criteria to consider are:

- Substitution effects, e.g. fossil fuel displacement

- Amount of $\mathrm{CO}_{2}$ fixed per tonne of product

- Duration of fixation (strictly in the context of life-cycle substitution effects)

- Energy storage benefit

- Electricity network balancing

- Reduction of renewable energy curtailment

\subsubsection{Creating a dedicated CCU Directive}

Due to lack of definition and legal grounding for several CCU processes, many stakeholders consider that a dedicated CCU Directive would be appropriate (M. Lewis, personal communication, September 26, 2017; D. Krämer, personal communication, December 1, 2016). Before proposing a new Directive, it is necessary to acknowledge the already dense policy landscape and the existing CCS Directive (2009/31/EC) and to ascertain whether there is a genuine gap. Moreover, the diversity amongst CCU technologies due to different sources, and value chain options and the variety of economic sectors such as petrochemicals and food, imply many possible overlaps and discrepancies, e.g. in double support for some options but not for others.

A precedent exists in the consolidation of seven directives such as the Waste Incineration Directive and the Large Combustion Plant Directive into the Industrial Emissions Directive, which helped to address inconsistencies across sectors (European Parliament, 2010). By contrast, aspects that could justify a separate Directive from the CCS Directive include the potential for significant waste recovery and feedstock production from sectors varying between horticultural production to waste incineration and steel production. Having a dedicated CCU Directive would provide investors the confidence that there is an established role for the technologies that reuse $\mathrm{CO}_{2}$.

\section{Conclusions}

While attention to general principles of innovation helps create sensible policies, sensitivity to a broad range of contextual variables is likely to be more important in the case of CCU policy than in other more conventional fields. Structural factors such as limited budgets, political cycles, data availability, and technological change, all 
complicate the design, implementation, and evaluation of CCU policy. Similarly, these factors can be regarded as part of the limitations of the research, which can be mitigated predominantly by revisiting the development of policy and engaging again with relevant stakeholders, again using cascade tracing of relevant actors to identify how constraints and motivations have evolved.

In this research, CCU stakeholders identified three main needs for policy that also need sequential policy interventions to support the whole innovation cycle:

- Market regulation

- Support for early development

- Incentives and guidance for deployment

Key aspects, such as the recognition of emissions as potential feedstocks for promising value chains such as mineralization for construction aggregates, were identified to exemplify policies at each stage of the value chain that require support, such as the classification of gas effluents as industrial wastes. Moreover, in addition to revisions of key directives on waste management and emissions trading, the work identified a significant gap in support for planning and financing connecting infrastructure. Two mechanisms that can be used to enable this development were identified. First, having a CCU dedicated tranche of funds in the New Entrants Reserve 400 of the EU ETS would help prevent carbon leakage, or off-shoring, of carbon intensive industries whilst promoting innovation in resource efficient products. Second, the Research and Innovation Strategies for Smart Specialization can significantly help de-risk parts of the industrial connectivity infrastructure that are hard for individual companies or local governments to finance. At the same time, it is necessary to include CCU infrastructure in the Connecting Europe Facility to leverage the regional strategies.

As an epilogue and a motive for further discussion, the list of recommendations that can help promote CCU in a more holistic way is summarized below:

- Groundwork preparation to strengthen regional economies through CCU activity, via material recovery, job creation and creation of expertise

- Improved End-of-Waste specifications

- Accounting for the renewable energy content and considering CCU-derived fuels as renewable at least in part.

- Inclusion of CCU in Smart Specialization Strategies

- Dedicated performance measurement and support formulae and tables

- Targeted public procurement

- Consider creating a dedicated CCU Directive

- Inclusion of CCU in the New Entrants Reserve "NER400"

- Dedicated resource efficiency and self-sufficiency label for CCU

- Publish a matrix of CCU benefits

In general, a main task for the CCU community is to continue identifying gaps and to back ongoing proposals with relevant evidence such as LCA data. 


\section{Acknowledgements}

The main findings presented in the paper arise from "enCO $\mathrm{CO}_{2} \mathrm{re}-$ Enabling $\mathrm{CO}_{2}$ Reuse", a research project financed by the European Institute of Innovation and Technology Climate Knowledge Innovation Community (Climate-KIC).

\section{References}

Adner, R., 2006. Match Your Innovation Strategy to Your Innovation Ecosystem. Harv. Bus. Rev. 84, 98-107.

Armstrong, K., Wilson, G., Saussez, G., Travaly, Y., Bolscher, H., Knippels, H., Brun, T., Farhoosh, R., Krämer, D., Rothengatter, N., Styring, P., Veenstra, E., Buck, L., Mooney, J., 2016. Joint Action Plan for. Smart $\mathrm{CO}_{2}$ Transformation in Europe $-\mathrm{CO}_{2}$ as a. resource. $\mathrm{SCO}_{2} \mathrm{~T}$ Consortium. $\mathrm{CO}_{2} \mathrm{Chem}$ Media and Publishing Limited, Sheffield.

Bui, M., Adjiman, C., Bardow, A., Anthony, E., Boston, A., Brown, S., Fennell, P., Fuss, S., Galindo, A., Hackett, L., Hallett, J., Herzog, H., Jackson, G., Kemper, J., Krevor, S., Maitland, G., Matuszewski, M., Metcalfe, I., Petit, C., Puxty, G., Reimer, J., Reiner, D., Rubin, E., Scott, S., Shah, N., Smit, B., Trusler, J., Webley, P., Wilcox, J., and Mac Dowell, Niall, 2018. Carbon capture and storage (CCS): the way forward. Energ. Environ. Sci. 11, 1062-1176. https://doi.org/10.1039/C7EE02342A

EC, 2011. COM (2011) 112 - A Roadmap for moving to a competitive low carbon economy in 2050. European Commission

EC, 2016. Proposal for a Directive of the European Parliament and of the Council on the promotion of the use of energy from renewable sources (recast) - COM(2016) 76. European Commission, Brussels.

EC S3Platform, 2017. European Commission Smart Specialisation Platform. http://s3platform.jrc.ec.europa.eu/(accessed January 2018)

European Parliament, 2003. Directive 2003/87/EC of the European Parliament and of the Council of 13 October 2003 establishing a scheme for greenhouse gas emission allowance trading within the Community and amending Council Directive 96/61/EC. Official Journal of the European Union, Brussels.

European Parliament, 2008. Directive 2008/98/EC of the European Parliament and of the Council of 19 November 2008 on waste and repealing certain Directives. Official Journal of the European Union, Brussels.

European Parliament, 2010. Directive 2010/75/EU of the European Parliament and of the Council of 24 November 2010 on industrial emissions (integrated pollution prevention and control) (Recast). Official Journal of the European Union, Brussels.

European Parliament, 2015. Directive 2015/1513/EU of the European Parliament and of the Council of 9 September 2015 amending Directive 98/70/EC relating to the quality of petrol and diesel fuels and amending Directive 2009/28/EC on the promotion of the use of energy from renewable sources. Official Journal of the European Union, Brussels. 
García, W., 2013. The European Chemical Industry perspective. IEA Global Industry Dialogue, Expert Review Workshop. IEA Publications, Paris.

Garcia-Gonzalez, L., Thomassen, G., Quaghebeur, M., Vanassche, S., Van Dael, M., De Wever, H., Vanden Berghe, J., 2016. Onderzoek naar mogelijk ondersteuningsbeleid m.b.t. nieuwe toepassingsmogelijkheden van $\mathrm{CO}_{2}$ als grondstof/feedstock. Vlaamse Instelling voor Technologisch Onderzoek and Departement Leefmilieu, Natuur en Energie.

GCCSI, 2011. Accelerating the uptake of CCS: Industrial use of captured carbon dioxide. Global Carbon Capture and Storage Institute \& Parsons Brinckerhoff, Brussels.

Ghinea, L., 2016. Carbon dioxide - turning an enemy into a valuable friend! SETIS Magazine, 11, 4.

Hills, C, 2016. Commercial capture and mineralisation of carbon in manufactured aggregates. SETIS Magazine, 11, 29-31.

Jenkins, J., Mansur, S., 2011. Bridging the clean energy Valleys of death - Helping American entrepreneurs meet the nation's energy innovation imperative. Breakthrough Institute, Oakland, California.

Miller, M., 2013. Renewable Energy Innovation Policy: Success Criteria and Strategies. IRENA Working Paper. International Renewable Energy Agency, Bonn

Patricio, J., Angelis-Dimakis, A., Castillo-Castillo, A., Kalmykova, Y. and Rosado, L., 2017. Method to identify opportunities for CCU at regional level - Matching sources and receivers. J. $\mathrm{CO}_{2}$ Utili. 22, 330-345. https://doi.org/10.1016/j.jcou.2017.10.009

Rex, E., Brunklaus, B., Lorentzon, K. (2015) Energy efficiency along the value chain Ways of working for increased competitiveness. SB Technical Research Institute of Sweden, Borås

Seppälä, T., Kalm, M., 2013. Profiting from Product Innovation: A Product Life Analysis of the Economic Geography of Value Added. The Research Institute of the Finnish Economy, Helsinki.

UBA, 2018. The Innovation Fund: How can it support low-carbon industry in Europe? - Design recommendations for the successor instrument to the NER 300 in Phase 4 of the EU ETS. Umweltbundesamt, Dessau-Roßlau, Germany.

UK Government, 2018. The UK Carbon Capture Usage and Storage deployment pathway - An Action Plan. 2018, London, UK

Villanueva, A., Delgado, L., Luo, Z., Eder, P., Catarino, A. S., Litten, D., 2010. Study on the selection of waste streams for end-of-waste assessment. European Commission Joint Research Centre - Institute for Prospective Technological Studies. Office for Official Publications of the European Communities, Luxembourg.

Wilson, G., Armstrong, K., Saussez,G., Travaly, Y., Bolscher, H., Knippels, H., Brun, T., Krämer, D., Rothengatter, N., Styring, P., Veenstra, E., Buck, L. and Mooney, J. 2016. A Strategic European Research and Innovation Agenda for Smart 
$\mathrm{CO}_{2}$ Transformation in Europe. Smart $\mathrm{CO}_{2}$ Transformation $\left(\mathrm{SCO}_{2} \mathrm{~T}\right)$ project. ISBN: 9780-9572588-5-3

Zhang, F., Sims Gallagher, K., 2013. Innovation and Technology Transfer Across Global Value Chains: Evidence from China's PV Industry. Energ. Policy. 94, 191-203. https://doi.org/10.1016/..enpol.2016.04.014 